\title{
The OP Protein Cage: A Versatile Molecular Delivery Platform
}

\author{
Thomas G.W. Edwardson $\$$, Mikail D. Levasseur, and Donald Hilvert ${ }^{\star}$
}

§SCS-DSM Award for the best virtual poster in Chemical Biology

\begin{abstract}
Well-defined containers constructed from multiple protein subunits are a unique class of nanomaterial useful in supramolecular chemistry and biology. These protein cages are widespread in nature, where they are responsible for a diversity of important tasks. As such, producing our own designer protein cages, complete with bespoke functionalities, is a promising avenue to new nanodevices, biotechnology and therapies. Herein, we describe how an artificial, computationally designed protein cage can be rationally engineered using supramolecular intuition to produce new functional capsules. Positive supercharging the interior cavity of this porous protein cage enables the efficient encapsulation of oligonucleotides by electrostatically-driven self-assembly. Moreover, the resulting cargo-loaded cages enter mammalian cells and release their cargo, for example siRNA which modulates gene expression. To expand the cargo scope of this proteinaceous container, a higher level of supramolecular complexity can also be introduced. Encapsulation of anionic surfactants affords protein-scaffolded micelles, which are capable of sequestering poorly water-soluble small molecules within their hydrophobic cores. These hybrid particles stably carry bioactive cargo and deliver it intracellularly, thereby increasing potency. Further development of these genetically-encoded materials is ongoing towards specific applications ranging from cell biology to medicine.
\end{abstract}

Keywords: Biomimetic · Drug delivery · Encapsulation · Protein engineering · siRNA

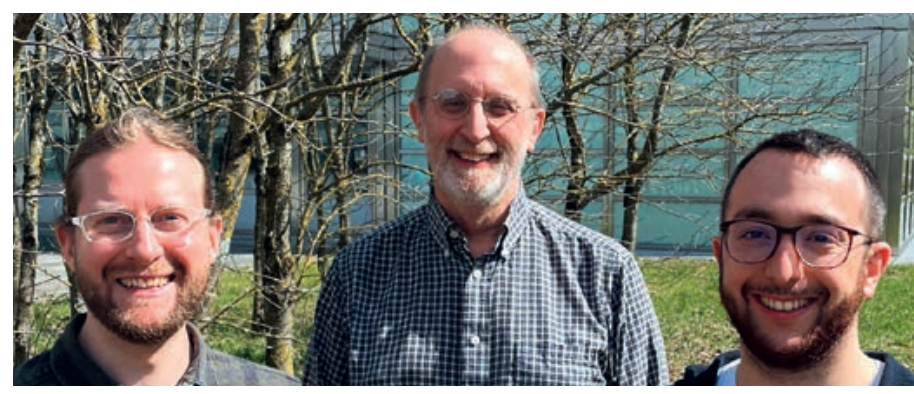

Thomas Edwardson (left) comes from the North-East of Scotland and studied chemistry at the University of Edinburgh, obtaining his MChem in 2008. In 2015, he completed a PhD in Chemistry at McGill University with Prof. Hanadi Sleiman, where he worked on DNA nanotechnology. Tom is currently a postdoctoral fellow at the ETH Zurich with Prof. Donald Hilvert, where he is further developing the OP protein cage platform.

Mikail Levasseur (right) comes from the Champagne region in France and obtained his Bachelor's and Master's degrees in Chemistry from ENSC Montpellier, France. After studying at the University of Oxford, and work experience with Johnson \& Johnson and Bayer, he finally moved to Switzerland to pursue his $\mathrm{PhD}$ at ETH Zurich. Under the supervision of Prof. Donald Hilvert, his focus is engineering protein cages for molecular delivery. He recently won the Startup Campus Award of the most innovative business idea based on the OP technology.

Donald Hilvert (middle) received a $\mathrm{PhD}$ in Chemistry from Columbia University, New York, in 1983. After postdoctoral stud-

*Correspondence: Prof. D. Hilvert, E-mail: donald.hilvert@org.chem.ethz.ch Laboratory of Organic Chemistry, ETH Zurich, 8093 Zurich, Switzerland ies at Rockefeller University, New York, he joined the faculty of the Scripps Research Institute at La Jolla, California, where he pursued his interests in chemical biology. In 1997 he moved to his current position as Professor of Chemistry at the ETH Zurich. His research program aims to understand the origins of enzyme catalysis, mimic and expand upon these properties, and engineer protein compartments for diverse applications.

\section{Introduction}

The reliable delivery of diverse molecules to specific tissues remains a grand challenge in medicine. As such, considerable effort and resources have been invested in the research of delivery systems that could function in the human body. In this field of study, the most popular carriers are undoubtedly nanoparticles, ${ }^{[1]}$ which may be comprised of lipids, polymers, metals, graphene, nucleic acids, peptides or combinations thereof.[2] While new studies appear on a daily basis, discrepancy between the number of research reports describing novel systems and actual clinical progress is concerning. ${ }^{[3]}$ Major reasons for this incongruity include the complexity of design, and thus challenging synthesis, of these functional nanocarriers, ${ }^{[4]}$ combined with concerns over the biocompatibility of synthetic materials. Taking a page from Nature's assembly manual, it is evident that protein nanotechnology has the potential to overcome some of these limitations. In the context of molecular delivery, proteins that form stable, structurally well-defined, shell-like nanoparticles are particularly interesting. ${ }^{5]}$ These protein cages can carry cargo within their inner cavities and display molecules on their surface, characteristics that provide ample opportunity to address current medical challenges or develop new modes of therapy. ${ }^{[6]}$

Protein cages abound in biology and are ideally suited for molecular delivery. ${ }^{[7]}$ From dangerous pathogens such as viruses ${ }^{[8]}$ to vital ion transporters like ferritin in our own bodies, ${ }^{[9]}$ these capsids carry diverse cargo to specific cell types. Found in all 
domains of life, biological capsules come in a multitude of sizes, shapes, complexity and dynamic properties. In addition to their cargo transport capabilities and generally negligible toxicity, genetic encoding and recombinant production are important enablers for the development of protein nanoparticle technology. Protein cages with atomically-defined structures can be produced at GMP-grade reliably and economically from large scale microbial fermentation. ${ }^{[10]}$

In the context of medicine, viruses are the most studied protein cages. ${ }^{[8]}$ Besides many vaccines that have had a profound effect on human civilization, ${ }^{[11]}$ they have also provided vectors for gene delivery and novel cancer therapies. ${ }^{[12]}$ However, for use as delivery vectors, safety concerns, such as immunogenicity and off-target effects, combined with difficulty of production are significant limitations. ${ }^{[13]}$ As such, bottom-up engineered viromimetic protein assemblies are an attractive alternative to viruses. ${ }^{[14]}$ Using either natural or artificial protein cages that have no relation to viral capsid proteins as a starting point, researchers have the opportunity to simultaneously elucidate the origins of viral function and create practical protein nanotechnology with tight control over structure and function. ${ }^{[15]}$ With this in mind, access to customized protein cages provided by computational protein design is a promising development. ${ }^{[16]}$ In this article, we discuss one such protein cage, its further engineering to create an oligonucleotide delivery vector, and its use as a scaffold for the formation of lipoprotein assemblies that deliver poorly soluble small molecule drugs.

\section{Oligonucleotide Delivery}

Oligonucleotide therapeutics are coming of age.[17] However, after much excitement in the early 2000s, which was initiated by the discovery of RNA interference (RNAi), ${ }^{[18]}$ the field has seen painfully slow translation to the clinic as the poor pharmacokinetic properties of oligonucleotides hampers their potential.[19] Currently, there are only a handful of antisense oligonucleotide (ASO) drugs on the market, although the recent approval of the first two short interfering RNA (siRNA) therapeutics is promis- ing. ${ }^{[17]}$ Nevertheless, the broad applicability of oligonucleotides in diverse disease areas has yet to be fully exploited and enabling technologies, especially in the area of cellular delivery, are sought after. To address this need, we set out to create a non-viral, protein-based oligonucleotide delivery system from an artificial protein cage. We have previously shown that non-viral lumazine synthase-based protein cages can be engineered and evolved to mimic viruses and encapsulate RNA molecules upon production in bacterial cells. ${ }^{[15 b, c]}$ However, for oligonucleotide delivery, the capacity to load any synthetic oligonucleotide, which may contain chemical modifications, in vitro is a desirable feature. We therefore opted to use a computationally designed porous protein cage as a starting point to generate such a system.

Recent advances in computer-aided design have provided access to a diverse set of artificial protein cages. ${ }^{[16]}$ These well-defined, symmetric capsules have proven useful for the engineering and evolution of viromimetics, ${ }^{[15 a, 20]}$ as cryo-EM imaging scaffolds, ${ }^{[21]}$ and as display platforms for diverse macromolecules, including enzymes, ${ }^{[22]}$ anti-freeze proteins ${ }^{[23]}$ and antigens. ${ }^{[24]}$ Due to its small size and porous structure, we chose one of the first designed protein cages, O3-33, ${ }^{[16 b]}$ which was created by Baker and co-workers. This cage is comprised of 24 monomers, which self-assemble upon expression in bacterial or mammalian cells to form a porous, yet highly stable, octahedral complex (Fig. 1a). Using O3-33 as a starting scaffold, we have developed a charge-based encapsulation system for delivery of oligonucleotides in mammalian cells (Fig. 1b). ${ }^{[25]}$ The delivery system, which is called $\mathrm{OP},{ }^{[25]}$ was created by mutation of lumenal amino acid residues cavity to arginine. Six residues were mutated per monomer (Fig. 1c), which through multimeric assembly, provide 144 positive charges within the $\sim 8 \mathrm{~nm}$ diameter interior cavity. Lumenal display of arginine or lysine residues is a common strategy employed by viruses to bind their negatively charged genomes, ${ }^{[26]}$ as electrostatics provides an efficient driving force for complex formation. However, the OP protein cage possesses structural features that are distinct from viral capsids. Crucially, the presence of six $\sim 3.5 \mathrm{~nm}$ pores in the capsid surface

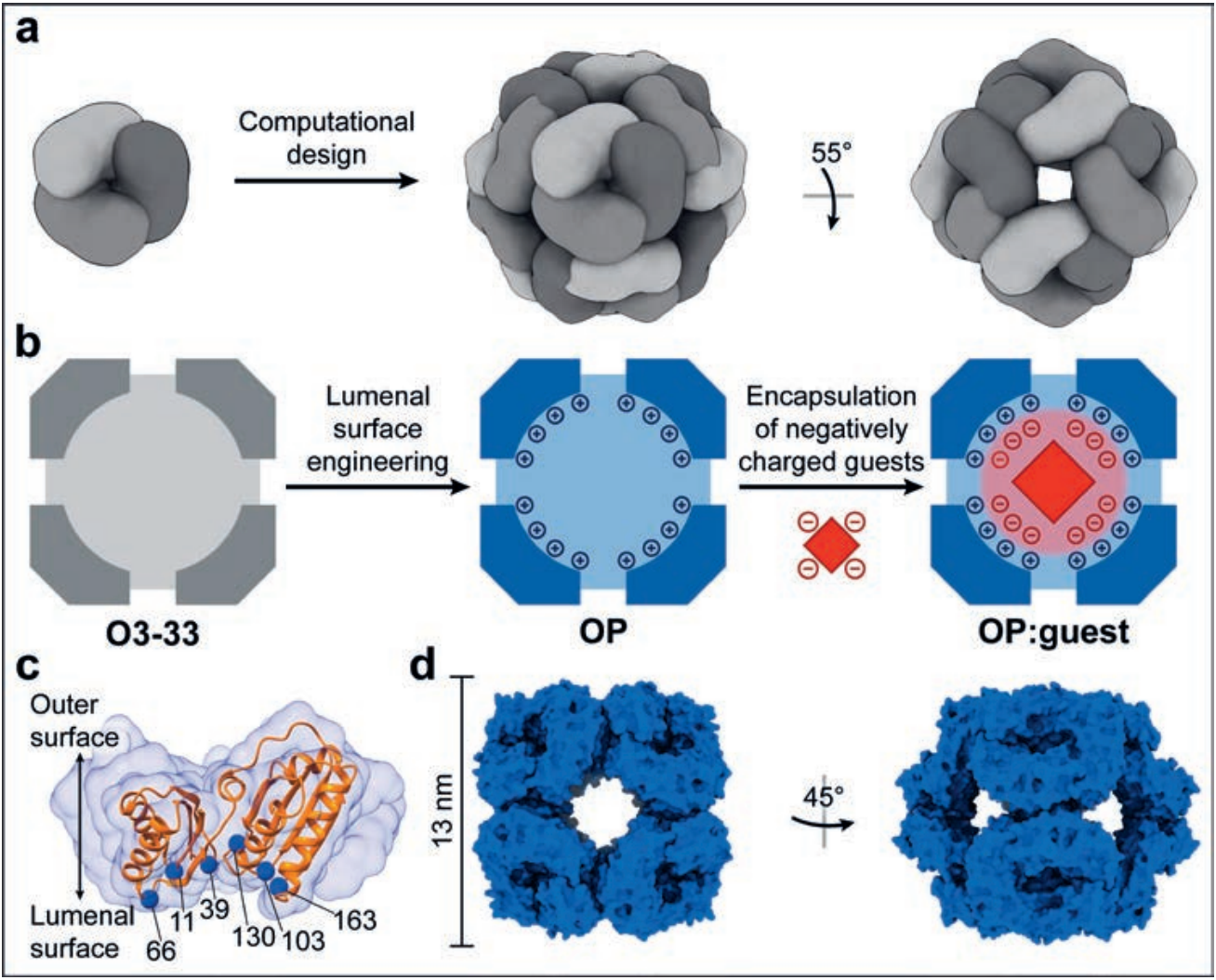

Fig. 1. Cage design and electrostatic loading. (a) The artificial protein cage, O3-33, was created by interface design of a naturally occurring homotrimeric protein (PDB ID: 3VCD). ${ }^{[16 b]}$ (b) The lumenal surface of O3-33 was engineered to present 144 positive charges per capsid, resulting in the OP protein cage, ${ }^{[25]}$ which efficiently encapsulates anionic cargo. (c) The six amino acid residues targeted for arginine mutation are shown as blue spheres in the monomer (orange ribbon), the transparent surface shows one trimer. (d) Surface representations, from X-ray diffraction data (PDB ID: 6FDB), of the OP protein cage viewed along the twofold (left) and fourfold (right) symmetry axes. The highly stable structure is unperturbed by positive supercharging. 
allow the loading and release of macromolecular cargo without disruption of the cage structure.

Structural analysis of the OP protein cage through X-ray crystallography and cryo-electron microscopy revealed that positive supercharging of the interior cavity had negligible effect on the protein structure when compared to the parent cage (Fig. 1d). ${ }^{[25,27]}$ This finding testifies to the robustness of the computational approach employed to generate the original structure.[16b] Furthermore, the OP cage retains high thermal stability, with a melting temperature of $94{ }^{\circ} \mathrm{C}$. [25]

The OP protein is produced in high titers $(>100 \mathrm{mg} / \mathrm{L}$ of culture) from standard Escherichia coli expression strains. ${ }^{[25]}$ After isolation and purification, OP is obtained as an empty cage ready for cargo loading. To investigate this, fluorimetry was used to monitor the encapsulation kinetics of dye-labeled synthetic oligonucleotides. The binding of short RNA or DNA strands occurs rapidly in standard buffers, such as phosphate buffered saline (PBS), and the resulting host-guest complexes are stable with subnanomolar dissociation constants. ${ }^{[25]}$ Importantly, as the driving force for encapsulation exploits the negatively charged phosphodiester backbone of the guests, the system is sequence agnostic.

Investigation of the cellular uptake profile of OP cages in vitro revealed that the OP cage efficiently enters various cell types without the need for additional modification. ${ }^{[25]}$ The capsid is taken up by cells through endocytosis (Fig. 2a,b), which is a typical process for particles in this size regime and also a cellular mechanism that is commonly exploited by viruses to gain entry to host cells. ${ }^{[28]}$ However, for the successful delivery of functional nucleic acids, such as ASOs or siRNA, which elicit their effect through interaction with cytosolic proteins and mRNA, the oligonucleotides must somehow escape from the endosomal pathway. ${ }^{[19]}$ To test this possibility, human cancer cells that stably express green fluorescent protein (GFP) were used, providing a simple readout to assess cy- tosolic siRNA delivery. Cells were treated with OP cages carrying an siRNA specifically designed to knockdown GFP expression. Measurement of GFP fluorescence from live cells by flow cytometry revealed that OP enabled efficient gene knockdown (Fig. 2c). The effect was comparable to a commercial Lipofectamine transfection agent. However, unlike this cationic lipid, OP caused no apparent toxicity. These data indicate that OP cages can not only enter cells, but somehow escape the endosome and release their functional oligonucleotide cargo. ${ }^{[25]}$

Viruses have evolved elegant molecular mechanisms to achieve endosomal escape, many of which make use of the acidic environment of mature endosomes. ${ }^{[28,29]}$ For example, influenza viruses display proteins that undergo $\mathrm{pH}$-inducible conformational changes, which initiate fusion with the endosomal membrane as the endosome acidifies. ${ }^{[30]}$ These conformational changes often stem from protonation of histidine, whose imidazole sidechain has a $\mathrm{p} K_{\mathrm{a}}$ well matched to endosomal maturation. ${ }^{[31]}$ Histidinerich peptides have also been shown to aid endosomal escape, ${ }^{[32]}$ either through the proton sponge effect[33] or permeabilization of the endosomal membrane. ${ }^{[34]}$ Each OP monomer has a C-terminal hexahistidine purification tag. As in viruses, due to the polyvalency inherent in multimeric assembly, any effect of this single hexahistidine tag will be amplified. The complete OP cage presents a total of 144 histidine residues on its exterior surface, which likely contribute significantly to interactions with cellular components. Indeed, removal of these histidine residues from the OP cage significantly reduced siRNA silencing efficacy.[25]

Once OP capsids have escaped to the cytosol, they must release their siRNA cargo to induce RNAi for target protein depletion. While OP:oligo complexes are highly stable, they form reversibly due to the porous structure of the cage. In the presence of high concentrations of competing guest molecules, such as tRNAs found in the cytosol, the encapsulated siRNA molecules are effectively washed out. ${ }^{[25]}$ This location-specific release behavior
Fig. 2. Cytoplasmic delivery of nucleic acid cargo. (a) OP can be efficiently loaded with a desired oligonucleotide by mixing in vitro. After cellular uptake via endocytosis, capsids escape the endosomes and release their cargo through displacement by cytosolic nucleic acids, such as tRNA. (b) Confocal fluorescence microscopy of HeLa cells treated with either free Atto488-DNA or Atto488-DNA packaged in OP cages. Blue, Nuclei (Hoechst 33342); Green, DNA (Atto488). The punctate structures are consistent with endosomal localization. (c) siRNA-induced knockdown of GFP expression in HeLa cells, monitored by flow cytometry $(n=3)$. Lipo:siRNA refers to Lipofectamine transfection.

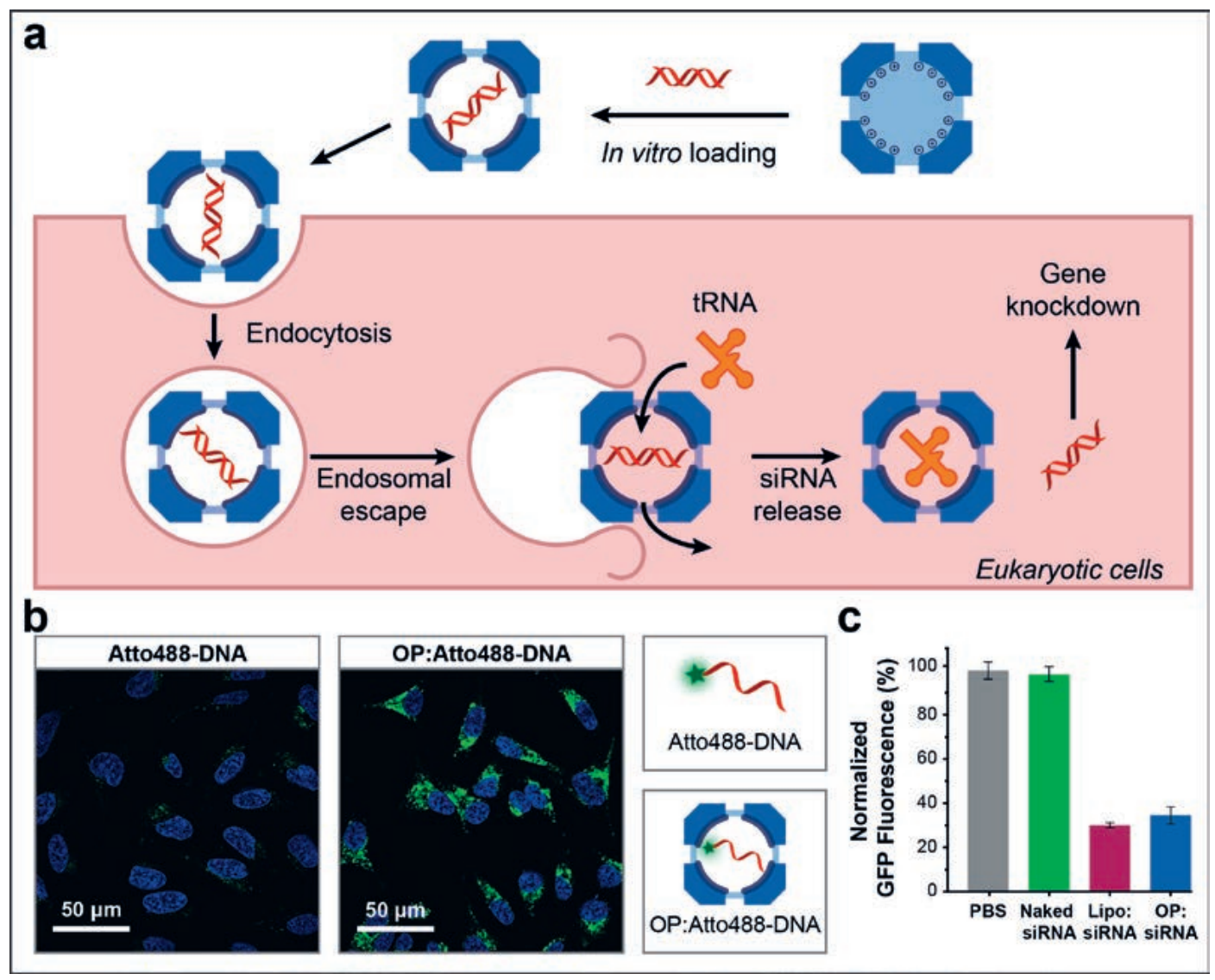


allows safe carriage of the fragile cargo molecules until they reach the site of action, where they are released to elicit their effect.

The emergent biological activity of the OP cage upon positive supercharging highlights the potential of inert protein scaffolds to be transformed into functional devices with only minimal mutation. Here, the robust porous structure is critical in enabling the in vitro loading and intracellular release of cargo. It is likely that other unique structural features, obtained through computational design and protein engineering, could provide access to entirely novel and practical functionalities.

\section{Small Molecule Loading}

Motivated by the biological performance of the OP cage generated through conservative engineering, we were interested in expanding the scope of this delivery platform to include other types of cargo. One possibility would be to invert the charge complementarity of the system, using a negatively charged capsid to encapsulate positively charged guests, such as proteins. This strategy has proven particularly successful with lumazine synthase assemblies. ${ }^{[5 \mathrm{c}]}$ Alternatively, by incorporating other classes of molecule in the assembly, cargo loading could be extended beyond simple electrostatic mechanisms.

Nature employs many hybrid systems, such as lipoproteins and protein-scaffolded vesicles, ${ }^{[35]}$ to transport hydrophobic molecules throughout the body. Serum lipoproteins carry molecules such as cholesterol, a vital component of cell membranes, and hormones, which have diverse functions. ${ }^{[35 a]}$ From a therapeutic perspective, methods to solubilize and transport small nonpolar molecules within the body are valuable. Approximately $40 \%$ of clinically approved drugs, and $90 \%$ of molecules in development, are poorly soluble in water and aqueous media. ${ }^{[36]}$ This creates a challenge for formulation chemists and imposes inherent limitations on drug discovery. As such, new strategies for the solubilization of bioactive molecules could improve current therapies and rescue potent therapeutics that may otherwise be lost in the pipeline. These platforms have the potential to simultaneously solve problems of bioavailability, serum protein binding, on-target/off-site effects and, therefore, systemic toxicity of chemotherapeutics.

Lipoproteins are a family of complexes comprising lipids, which provide a hydrophobic core capable of loading nonpolar molecules, and proteins, which act as structural scaffolds and recognition elements for cells. ${ }^{[35 a]}$ We sought to mimic the function of these transporters, albeit through an alternative architecture, using the OP protein cage as a scaffold. Our approach relies on the combination of two orthogonal self-assembly modes: electrostatic and hydrophobic (Fig. 3a). Anionic surfactants are drawn into the lumen of the positively charged cage and, due to their high effective concentration, phase separate to form a micellar core within the interior cavity. In this manner, OP acts as a chaperone, stabilizing the formation of micelles at concentrations well below the critical aggregation concentration of the amphiphiles. On the other hand, the micellar core provides a means to encapsulate small nonpolar molecules, which quickly partition into the favorable hydrophobic environment.

We have recently demonstrated the self-assembly of lipoprotein-mimics using OP and sodium dodecyl sulfate (SDS).[27] This surfactant is an FDA-approved food additive and is found in many cosmetic and household products. ${ }^{[37]}$ The OP cage can sequester SDS molecules and template the formation of stable protein-scaffolded micelles within its lumen. These complexes were found to have an optimal stoichiometry (1:800, OP:SDS) that correlates with the size of the interior cavity. Importantly, structural analysis of these assemblies by a suite of biophysical and structural biology techniques showed that protein structure was unperturbed. [27]

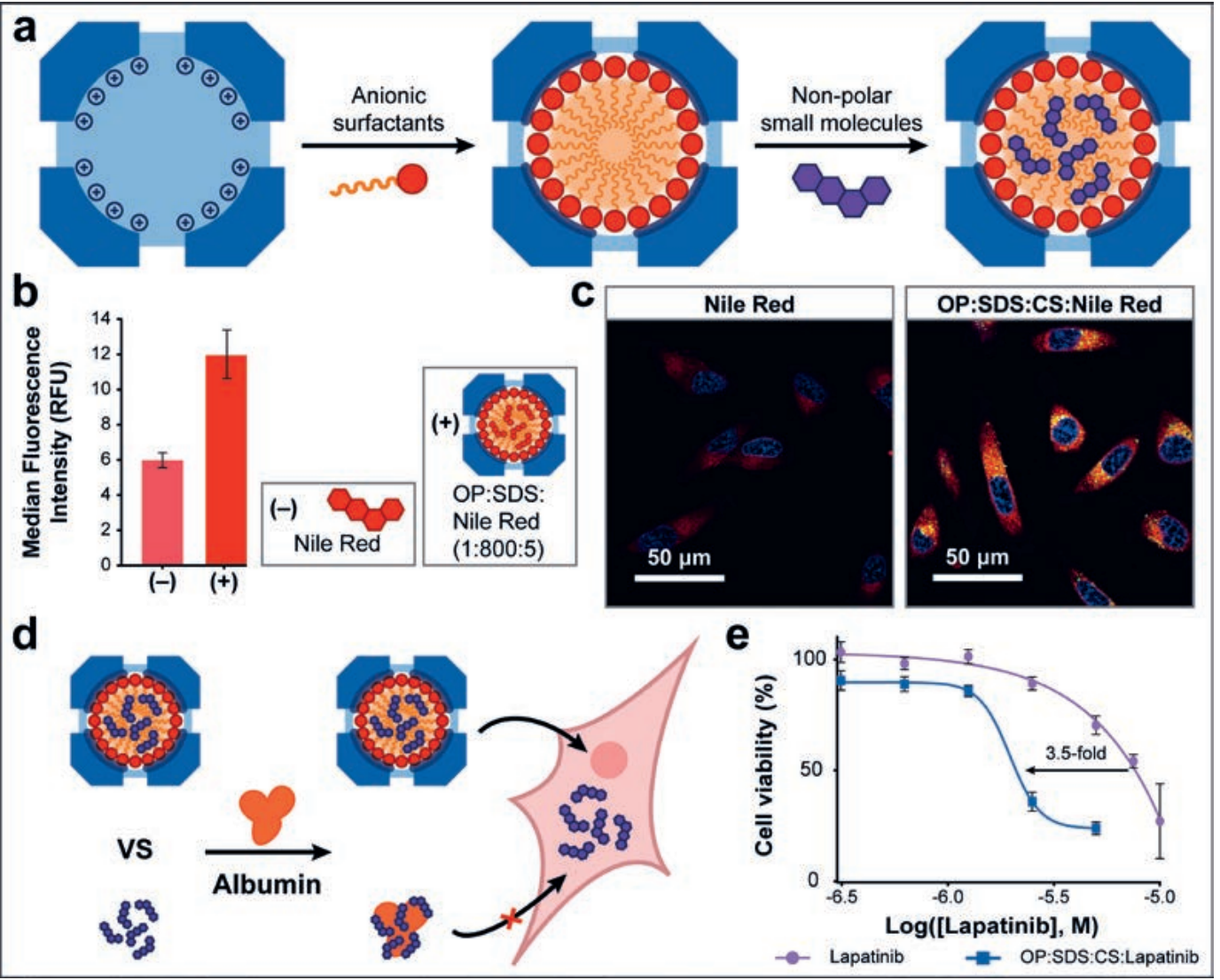

Fig. 3. Self-assembly of lipoprotein mimics for intracellular delivery of small molecules. (a) Two-tier encapsulation concept: electrostatic attraction drives the encapsulation of anionic surfactants, which phase separate due to their high effective concentration, forming micellar aggregates within OP cages. The hydrocarbon core of these stable protein-surfactant complexes then sequesters nonpolar small molecules by means of the hydrophobic effect. (b) Flow cytometry dataset for the delivery of Nile Red by OP:SDS complexes in HeLa cells $(n=3)$. (c) Confocal fluorescence microscopy of HeLa cells treated with either free Nile Red or Nile Red packaged in OP:SDS:CS complexes. Blue, Nuclei (Hoechst 33342); Green, OP (Atto425); Red, Nile Red. (d) Whereas free lapatinib is poorly soluble and sequestered by serum albumin, OP:SDS:CS complexes solubilize lapatinib, prevent its binding to albumin and carry it into cells. (e) Dose-response comparison of cytotoxicity induced by free lapatinib or lapatinib packaged in OP:SDS:CS complexes in HeLa cells $(n=6)$. 
To determine whether these micelle-filled capsids could encapsulate small hydrophobic molecules as intended, we used the solvatochromic fluorophore Nile Red. ${ }^{[38]}$ This dye is essentially non-emissive in aqueous solution, but exhibits strong fluorescence emission in nonpolar environments. As well as confirming the presence of a hydrophobic core within OP:SDS complexes, titration experiments with Nile Red revealed a loading capacity of $c a .20$ molecules per capsid. [27] With the inherent ability of OP cages to enter mammalian cells in mind we tested the OP:SDS complexes for intracellular delivery of small molecules.

Human cancer cells were treated with either free Nile Red or the molecule packaged in OP:SDS complexes and analyzed by flow cytometry. Although Nile Red is routinely used as a lipid stain and exhibits significant cell permeability as a free molecule, packaging in OP:SDS complexes provided a two-fold increase in cellular uptake (Fig. 3b). These results were confirmed by confocal microscopy, which further revealed that Nile Red had diffused throughout the cytoplasm (Fig. 3c). Extrapolating from these results, we also used OP to encapsulate and deliver a biologically active molecule with a cytoplasmic target. We chose the chemotherapeutic lapatinib, a dual tyrosine kinase inhibitor targeting EGFR and HER2, which is used to treat HER2-positive cancers. ${ }^{[39]}$ This drug suffers from poor aqueous solubility, low permeability and very high serum protein binding. ${ }^{[40]}$ As such, lapatinib represents an ideal model compound to demonstrate the benefit of a lipoprotein-like delivery system.

Initial tests indicated that lapatinib is not stably encapsulated in OP:SDS complexes. However, we hypothesized that this problem could be overcome by altering the physical properties of the hydrophobic core. In practical terms, this can be accomplished simply by altering the lipid composition. Indeed, replacement of $25 \mathrm{~mol} \%$ of the SDS with cholesterol sulfate (CS), an endogenous steroid, afforded protein-micelle complexes that efficiently encapsulated lapatinib. ${ }^{[27]}$ The addition of cholesterol sulfate increased drug binding affinity significantly. Not only was lapatinib stably retained in the presence of high concentrations of serum albumin, but OP:SDS:CS complexes could even sequester lapatinib that was pre-bound to serum albumin. These results highlight the advantage of a modular self-assembled delivery system that can be easily customized to transport different molecules with defined loading and release kinetics.

With stably encapsulated lapatinib, we tested the ability of the OP complexes to enhance the cytotoxicity of the drug. We expected that preventing binding to serum albumin present in the cell culture medium, combined with the efficient cellular uptake of OP cages, would lead to enhanced activity (Fig. 3d). Indeed, the OP delivery system provided a 3.5 -fold decrease in IC50 in comparison to the free drug (Fig. 3e), ${ }^{[27]}$ an enhancement that is better than other reported lapatinib nano-delivery systems. ${ }^{[41]}$

\section{Conclusions and Outlook}

Starting from an artificial protein assembly with a unique supramolecular structure, we have shown that a minimal approach to mutation can result in surprising functionality. For cellular delivery of oligonucleotides, a combination of porosity and compartmentalized positive charge afforded a carrier system that uses alternative solutions to basic viral functions. Expansion of this charge-based encapsulation platform to include lipids provided analogues of serum lipoproteins. The simple supramolecular concepts employed to generate these functional assemblies from a starting scaffold could be applied to other protein cage structures, of which many are available. ${ }^{[5 a, c, 16 a, c, d, f]}$

Our results demonstrate that OP efficiently penetrates a range of mammalian cell types. Given its broad cargo tolerance, this engineered molecular container could find application as a transfection agent for nucleic acids, and delivery vehicle for hydropho- bic drugs and imaging agents. Protein-based molecular delivery strategies have great potential as they are biodegradable, reliably produced at large scale and offer broad scope for genetic, covalent and non-covalent modification. Antibody-drug conjugates (ADCs) are an excellent example, ${ }^{[42]}$ combining the advantages of proteins and small molecule therapeutics to promote accumulation of cytotoxic molecules at specific tumor sites. However, the unstable and random attachment of only a small number of molecules to antibodies, as well as linkers that tend to induce ADC aggregation are serious limitations to this approach. ${ }^{[42]}$ Here, protein cages exhibit distinct advantages related to their high payload capacity, the non-covalent nature of the interaction with encapsulated molecules, and the ability to protect their cargo from degradation. Although such systems face major obstacles including short elimination half-life, low tissue penetration capacity, and immunogenicity, ${ }^{[43]}$ ongoing advances in protein engineering infuse optimism, as these genetically encoded nanoparticles are compatible with the ever growing toolbox of biotechnology.

Gaining a deeper understanding of the intricate structure and function of Nature's molecular machinery can help us design our own nanodevices. An important step towards this goal is the generation of robust model systems that enable systematic investigations. The simple yet effective delivery system presented here provides such a platform; to ask fundamental questions regarding virus and lipoprotein function, while providing a means to overcome current challenges in biology and medicine.

\section{Acknowledgements}

T.E. gratefully acknowledges the SCS and DSM for the generous award. We would like to thank Takahiro Mori and Stephan Tetter for their contributions to the experimental work described here. This work was supported by the ETH Zurich and the European Research Council (Advanced ERC Grant ERC-AdG-2012-321295 to D.H.). T.E. is very grateful to the Human Frontier Science Program for a Long-term fellowship.

Received: January 30, 2021

[1] J. K. Patra, G. Das, L. F. Fraceto, E. V. Ramos Campos, M. del Pilar Rodriguez-Torres, L. S. Acosta-Torres, L. A. Diaz-Torres, R. Grillo, M. K. Swamy, S. Sharma, S. Habtematiam, H.-S. Shin, J. Nanobiotechnol. 2018, 16, 71, https://doi.org/10.1186/s12951-018-0392-8

[2] a) D. A. Giljohann, D. S. Seferos, W. L. Daniel, M. D. Massich P. C. Patel, C. A. Mirkin, Angew. Chem. Int. Ed. 2010, 49, 3280, https://doi.org/10.1002/anie.200904359; b) A. Z. Wang, R. Langer, O. C. Farokhzad, Аnnu. Rev. Med. 2012, 63, 185, https://doi.org/10.1146/annurev-med-040210-162544; c) Y. Zhang, D Petibone, M. Mahmood, A. Karmakar, D. Casciano, S. Ali, A. S. Biris, Drug Metab. Rev. 2014, 46, 232, https://doi.org/10.3109/03602532.20 14.883406; d) C. Zylberberg, S. Matosevic, Drug Deliv. 2016, 23, 3319, https://doi.org/10.1080/10717544.2016.1177136; e) K. E. Bujold, A Lacroix, H. F. Sleiman, Chem 2018, 4, 495, https://doi.org/10.1016/j. chempr.2018.02.005; f) C. D. Spicer, C. Jumeaux, B. Gupta, M. M. Stevens, Chem. Soc. Rev. 2018, 47, 3574, https://doi.org/10.1039/C7CS00877E; g) S. Matoori, J.-C. Leroux, Mater. Horiz. 2020, 7, 1297, https://doi.org/10.1039/ C9MH01669D; h) M. J. Mitchell, M. M. Billingsley, R. M. Haley, M. E. Wechsler, N. A. Peppas, R. Langer, Nat. Rev. Drug Discov. 2020, https://doi.org/10.1038/s41573-020-0090-8.

[3] V. J. Venditto, F. C. Szoka, Adv. Drug Del. Rev. 2013, 65, 80, https://doi.org/10.1016/j.addr.2012.09.038.

[4] J. C. Leroux, Angew. Chem. Int. Ed. 2017, 56, 15170, https://doi.org/10.1002/anie.201709002.

[5] a) J. G. Heddle, S. Chakraborti, K. Iwasaki, Curr. Opin. Struct. Biol. 2017, 43, 148, https://doi.org/10.1016/j.sbi.2017.03.007; b) M. Slininger Lee, D. Tullman-Ercek, Curr. Opin. Sys. Biol. 2017, 5, 16, https://doi.org/10.1016/j.coisb.2017.05.017; c) Y. Azuma, T. G. W. Edwardson, D. Hilvert, Chem. Soc. Rev. 2018, 47, 3543, https://doi.org/10.1039/C8CS00154E.

[6] a) H. E. van Kan-Davelaar, J. C. M. van Hest, J. J. L. M Cornelissen, M. S. T. Koay, Br. J. Pharmacol. 2014, 171, 4001, https://doi.org/10.1111/bph.12662; b) A. M. Wen, N. F. Steinmetz, Chem. Soc. Rev. 2016, 45, 4074, https://doi.org/10.1039/C5CS00287G. 
[7] C. Chowdhury, S. Sinha, S. Chun, T. O. Yeates, T. A. Bobik, Microbiol. Mol. Biol. Rev. 2014, 78, 438, https://doi.org/10.1128/MMBR.00009-14.

[8] H. Lodish, A. Berk, S. L. Zipursky, P. Matsudaira, D. Baltimore, J. Darnell, in 'Molecular Cell Biology', 4th ed., W.H. Freeman, New York, 2000, https://doi.org/10.1016/S1470-8175(01)00023-6.

[9] X. Liu, E. C. Theil, Acc. Chem. Res. 2005, 38, 167, https://doi.org/10.1021/ar0302336.

[10] S. K. Gupta, P. Shukla, Front. Pharmacol. 2017, 8, https://doi.org/10.3389/fphar.2017.00419.

[11] S. A. Plotkin, S. L. Plotkin, Nat. Rev. Microbiol. 2011, 9, 889, https://doi.org/10.1038/nrmicro2668.

[12] a) J. Pol, G. Kroemer, L. Galluzzi, Oncoimmunology 2015, 5, e1115641, https://doi.org/10.1080/2162402X.2015.1115641; b) K. Lundstrom, Diseases 2018, 6, 42, https://doi.org/10.3390/diseases6020042.

[13] N. Nayerossadat, T. Maedeh, P. A. Ali, Adv. Biomed. Res. 2012, 1, 27, https://doi.org/10.4103/2277-9175.98152.

[14] T. G. W. Edwardson, D. Hilvert, J. Am. Chem. Soc. 2019, 141, 9432, https://doi.org/10.1021/jacs.9b03705.

[15] a) G. L. Butterfield, M. J.. Lajoie, H. H. Gustafson, D. L. Sellers, U. Nattermann, D. Ellis, J. B. Bale, S. Ke, G. H. Lenz, A. Yehdego, R. Ravichandran, S. H. Pun, N. P. King, D. Baker, Nature 2017, 552, 415, https://doi.org/10.1038/nature25157; b) Y. Azuma, T. G. W. Edwardson, N. Terasaka, D. Hilvert, J. Am. Chem. Soc. 2018, 140, 566, https://doi.org/10.1021/jacs.7b10798; c) N. Terasaka, Y. Azuma, D. Hilvert, Proc. Natl. Acad. Sci. U.S.A. 2018, 115, 5432, https://doi.org/10.1073/pnas.1800527115.

[16] a) J. E. Padilla, C. Colovos, T. O. Yeates, Proc. Natl. Acad. Sci. U.S.A. 2001， 98， 2217, https://doi.org/10.1073/pnas.041614998; b) N. P. King, W. Sheffler, M. R. Sawaya, B. S. Vollmar, J. P. Sumida, I. André, T. Gonen, T. O. Yeates, D. Baker, Science 2012, 336, 1171, https://doi.org/10.1126/science.1219364; c) J. M. Fletcher, R. L. Harnimann, F. R. H. Barnes, A. L. Boyle, A. Collins, J. Mantell, T. H. Sharp, M. Antognozzi, P. J. Booth, N. Linden, M. J. Miles, R. B. Sessions, P. Verkade, D. N. Woolfson, Science 2013, 340, 595, https://doi.org/10.1126/science.1233936; d) N. P. King, J. B. Bale, W. Sheffler, D. E. McNamara, S. Gonen, T. Gonen, T. O. Yeates, D. Baker, Nature 2014, 510, 103, https://doi.org/10.1038/nature13404; e) J. B. Bale, S. Gonen, Y. Liu, W. Sheffler, D. Ellis, C. Thomas, D. Cascio, T. O. Yeates, T. Gonen, N. P. King, D. Baker, Science 2016, 353, 389, https://doi.org/ 10.1126/science.aaf8818; f) K. A. Cannon, V. N. Nguyen, C. Morgan, T. O. Yeates, ACS Synth. Biol. 2020, 9, 517, https://doi.org/10.1021/acssynbio.9b00392

[17] B. Hu, L. Zhong, Y. Weng, L. Peng, Y. Huang, Y. Zhao, X.J. Liang, Signal Transduct. Target. Ther. 2020, 5, 101 , https://doi.org/10.1038/s41392-020-0207-X.

[18] A. Fire, S. Xu, M. K. Montgomery, S. A. Kostas, S. E. Driver, C. C. Mello, Nature 1998, 391, 806, https://doi.org/10.1038/35888.

[19] S. F. Dowdy, Nat. Biotechnol. 2017, 35, 222, https://doi.org/10.1038/nbt.3802

[20] J. Votteler, C. Ogohara, S. Yi, Y. Hsia, U. Nattermann, D. M. Belnap, N. P. King, W. I. Sundquist, Nature 2016, 540, 292, https://doi.org/10.1038/nature20607.

[21] Y. Liu, D. T. Huynh, T. O. Yeates, Nat. Commun. 2019, 10, 1864 https://doi.org/10.1038/s41467-019-09836-0.

[22] S. A. McConnell, K. A. Cannon, C. Morgan, R. McAllister, B. R Amer, R. T. Clubb, T. O. Yeates, ACS Synth. Biol. 2020, 9, 381, https://doi.org/10.1021/acssynbio.9b00407.

[23] S. W. Phippen, C. A. Stevens, T. D. R. Vance, N. P. King, D. Baker, P. L. Davies, Biochemistry 2016, 55, 6811, https://doi.org/10.1021/acs.biochem.6b00864.

[24] a) J. Marcandalli, B. Fiala, S. Ols, M. Perotti, W. de van der Schueren, J. Snijder, E. Hodge, M. Benhaim, R. Ravichndran, L. Carter, W. Sheffler, L. Brunner, M. Lawrenz, P. Dubois, A. Lanzavecchia, F. Sallusto, K. K. Lee, D. Veesler, C. E. Correnti, L. J. Stewart, D. Baker, K. Loré, L. Perez, N. P. King, Cell 2019, 176, 1420, https://doi.org/10.1016/j.cell.2019.01.046; b) P. J. M. Brouwer, A. Antanasijevic, Z. Berndsen, A. Yasmeen, B. Fiala, T. P. L. Bijl, I. Bontjer, J. B. Bale, W. Sheffler, J. D. Allen, A. Schorcht, J. A. Burger, M. Camacho, D. Ellis, C. A. Cottrell, A.-J. Behrens, M. Catalano, I. del Moral-Sánchez, T. J. Ketas, C. LaBranche, M. J. van Gils, K. Sliepen, L. J. Stewart, M. Crispin, D. C. Montefiori, D. Baker, J. P. Moore, P. J. Klasse,
A. B. Ward, N. P. King, R. W. Sanders Nat. Commun. 2019, 10, 4272 , https://doi.org/10.1038/s41467-019-12080-1; c) A. C. Walls, B. Fiala A. Schäfer, S. Wrenn, M. N. Pham, M. Murphy, L. V. Tse, L. Shehata, M. A. O'Connor, C. Chen, M. J. Navarro, M. C. Miranda, D. Pettie, R. Ravichandran, J. C. Kraft, C. Ogohara, A. Palser, S. Chalk, E. C. Lee, K. Guerriero, E. Kepl, C. M. Chow, C. Sydeman, E. A. Hodge, B. Brown, J. T. Fuller, K. H. Dinnon, L. E. Gralinski, S. R. Leist, K. L. Gully, T. B. Lewis, M. Guttman, H. Y. Chu, K. K. Lee, D. H. Fuller, R. S. Baric, P. Kellam, L. Carter, M. Pepper, T. P. Sheahan, D. Veesler, N. P. King Cell 2020, 183, 1367, https://doi.org/10.1016/j.cell.2020.10.043.

[25] T. G. W. Edwardson, T. Mori, D. Hilvert, J. Am. Chem. Soc. 2018, 140, 10439, https://doi.org/10.1021/jacs.8b06442.

[26] V. A. Belyi, M. Muthukumar, Proc. Natl. Acad. Sci. U.S.A. 2006, 103, 17174, https://doi.org/10.1073/pnas.0608311103.

[27] T. G. W. Edwardson, S. Tetter, D. Hilvert, Nat. Commun. 2020, 11, 5410, https://doi.org/10.1038/s41467-020-19112-1.

[28] J. Mercer, M. Schelhaas, A. Helenius, Annu. Rev. Biochem. 2010, 79, 803, https://doi.org/10.1146/annurev-biochem-060208-104626.

[29] A. E. Smith, A. Helenius, Science 2004, 304, 237, https://doi.org/10.1126/science.1094823.

[30] J. J. Skehel, D. C. Wiley, Annu. Rev. Biochem. 2000, 69, 531, https://doi.org/10.1146/annurev.biochem.69.1.531.

[31] a) D. S. Mueller, T. Kampmann, R. Yennamalli, P. R. Young, B. Kobe, A. E. Mark, Biochem. Soc. Trans. 2008, 36, 43, https://doi.org/10.1042/ bst0360043; b) T. Kampmann, D. S. Mueller, A. E. Mark, P. R. Young, B. Kobe, Structure 2006, 14, 1481, https://doi.org/10.1016/j.str.2006.07.011.

[32] a) P. Midoux, E. LeCam, D. Coulaud, E. Delain, C. Pichon, Somatic Cell Mol. Genet. 2002, 27, 27, https://doi.org/10.1023/A:1022931923153; b) C. Pichon, C. Gonçalves, P. Midoux, Adv. Drug Del. Rev. 2001, 53, 75, https://doi.org/10.1016/S0169-409X(01)00221-6.

[33] J.-P. Behr, CHIMIA 1997, 51, 34

[34] P. Midoux, A. Kichler, V. Boutin, J. C. Maurizot, M. Monsigny, Bioconj. Chem. 1998, 9, 260, https://doi.org/10.1021/bc9701611.

[35] a) R. W. Mahley, T. L. Innerarity, S. C. Rall, Jr., K. H. Weisgraber, J. Lipid Res. 1984, 25, 1277; b) J. A. Olzmann, P. Carvalho, Nat. Rev. Mol. Cell Biol. 2019, 20, 137, https://doi.org/10.1038/s41580-018-0085-z.

[36] T. Loftsson, M. E. Brewster, J. Pharm. Pharmacol. 2010, 62, 1607, https://doi.org/10.1111/j.2042-7158.2010.01030.x.

[37] C. A. Bondi, J. L. Marks, L. B. Wroblewski, H. S. Raatikainen, S R. Lenox, K. E. Gebhardt, Environ. Health Insights 2015, 9, 27, https://doi.org/10.4137/EHI.S31765.

[38] P. Greenspan, E. P. Mayer, S. D. Fowler, J. Cell Biol. 1985, 100, 965, https://doi.org/10.1083/jcb.100.3.965.

[39] B. Moy, P. E. Goss, Oncologist 2006, 11, 1047 https://doi.org/10.1634/theoncologist.11-10-1047.

[40] a) P. J. Medina, S. Goodin, Clin. Ther. 2008, 30, 1426 https://doi.org/10.1016/j.clinthera.2008.08.008; b) N. R. Budha, A. Frymoyer, G. S. Smelick, J. Y. Jin, M. R. Yago, M. J. Dressler, S. N. Holden, L. Z. Benet, J. A. Ware, Clin. Pharmacol. Ther. 2012, 92, 203, https://doi.org/10.1038/clpt.2012.73.

[41] G. V. Bonde, S. K. Yadav, S. Chauhan, P. Mittal, G. Ajmal, S. Thokala, B. Mishra, Expert Opin. Drug. Deliv. 2018, 15, 495, https://doi.org/10.1080/17425247.2018.1449832.

[42] N. Joubert, A. Beck, C. Dumontet, C. Denevault-Sabourin, Pharmaceuticals 2020, 13, 245, https://doi.org/10.3390/ph13090245.

[43] L.-P. Wu, D. Wang, Z. Li, Mater. Sci. Eng. C 2020, 106, 110302, https://doi.org/10.1016/j.msec.2019.110302.

\section{License and Terms}

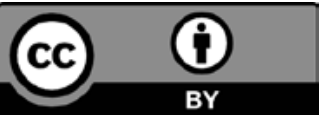

This is an Open Access article under the terms of the Creative Commons Attribution License CC BY 4.0. The material may not be used for commercial purposes.

The license is subject to the CHIMIA terms and conditions: (http:// chimia.ch/component/sppagebuilder/?view=page \&id=12).

The definitive version of this article is the electronic one that can be found at https://doi.org/10.2533/chimia.2021.323 